\title{
Pattern of Maxillofacial Trauma among Patients with Head Injuries
}

\author{
Dr. Abul Hasnat ${ }^{1}$, Dr. A.K.M. Erfanul Hoque ${ }^{2}$, Dr. Md. Selim-Ul-Azam³, \\ Dr. Mohammad Kamrujjaman ${ }^{4}$, Dr. Mahmuda Akhtar ${ }^{5}$
}

Received: 15 February 2017 Accepted: 09 April 2017

Abstract:

Background: Patients with maxillofacial trauma are at high risk of having traumatic cranial injuries. Prompt determination of head injury in these patients is crucial for improving patient's survival and smooth recovery. Objective: The purpose of this study was to find out the pattern of maxillofacial injuries in a patient with head injuries and to study their relationship. Study design: A prospective Cross-sectional descriptive study was made over 60 patients. Study setting and period: The study was conducted in the Department of Oral \& Maxillofacial Surgery, Bangabandhu Sheikh Mujib Medical University, Shahbag, Dhaka-1000 from May 2010 to April 2011. Participants: Sixty patients with maxillofacial and head injuries were selected for the study. Methods: It was a prospective cross-sectional descriptive hospital based study. 60 patients who were diagnosed of having concomitant maxillofacial and head injuries were included in this study. Information's based on age, sex, mode of injury, pattern of facial and head injury, GCS score and type of head injury were taken for each case. Appropriate skull $X$-ray was done for all patients with maxillofacial injury and patient's with initial sign of neurological deficit an initial CT scan of brain was done. Data was analyzed using the SPSS program. Results: Majority of the patients were in the 2 nd to 4 th decade (75\%) with a male to female ratio of 7.57:1 Motor vehicle accidents were the most common cause of injury (60\%), followed by fall from height (13.3\%).Mandible was the most commonly fractured facial bone (36.67\%), followed by midface fracture (18.3\%).Majority of the patients had moderate head injury and were managed conservatively. Among depressed fracture of skull, frontal bone was most commonly affected. Conclusion: Adult males were most common victims in craniofacial trauma, and road traffic accidents were responsible for the majority. Most of the patients sustained moderate head injuries and were managed conservatively. Open reduction and internal fixation with miniplates were used for displaced facial bone fractures.

Key Words: Maxillofacial trauma, head injury, facial bone fracture, Glasgow coma scale.

\section{Introduction:}

Maxillofacial trauma and concomitant head injuries carry the significant potential for mortality and neurological morbidity. Maxillofacial trauma can occur as an isolated injury or in combination with other severe injuries ${ }^{1}$. Patients with maxillofacial trauma may present with associated intracranial, pulmonary, intra-abdominal or extremity injuries ${ }^{2,3}$. A close relationship between maxillofacial fracture and intracranial injury has been reported in many articles ${ }^{4-6}$. In many countries, cranial injury has been found to be the most common accompanying organ injury in patients with maxillofacial trauma ${ }^{3,4}$. These includes head traumas, intracranial hemorrhages, closed head traumas (brain contusion or laceration), or fractures. Generally, the presence of emesis, vomiting, loss of consciousness, or a low Glasgow Coma Scale (GCS) score are important findings for suspicion of a cranial injury. However, in patients with maxillofacial trauma, head trauma may also be seen without observing the suggestive findings ${ }^{6}$.

The etiology of maxillofacial injuries varies from one country to another and even within the same depending on the prevailing socioeconomic, cultural and environmental factors. Earlier studies from Europe and America revealed that Road Traffic crashes

1. BDS, FCPS (OMFS), Asst Professor \& Head, Oral \& Maxillofacial Surg, Dhaka Community Medical College

2. FCPS (Part-II) Examinee (OMFS)

3. FCPS Part-II Examinee (OMFS)

4. BDS, FCPS (OMFS), Asst. Professor \& Head, Oral \& Maxillofacial Surgery, Bangladesh Dental College

5. BDS, MS, FCPS, Associate Prof, Oral \& Maxillofacial Surg, Bangabandhu Sheikh Mujib Medical University

Correspondence : Dr. Abul Hasnat, e-mail: abulhasnat41@yahoo.com, Cell: 01717-300982, 01617-300982 
(RTC) were the most frequent cause of facial injuries ${ }^{7,8}$ However more recent studies have shown that assault is now the most common cause of maxillofacial injuries in developed countries ${ }^{9,10}$ where as traffic accidents remain the most frequent cause in many developing countries ${ }^{11}$ like Bangladesh. Others causes of maxillofacial trauma are fall from height, assaults, altercation, pedestrian injury, home and industrial accidents and athletic injuries, in descending order of frequency ${ }^{12}$.

The peak age of incidence of maxillofacial injuries among $21-30$ years ${ }^{13}$ and more males are involved in maxillofacial injuries than females ${ }^{14}$. Children are uniquely susceptible to maxillofacial injury because of their disproportionate cranial-body mass ratio ${ }^{15}$. Patients older than 65 years account for approximately $1 \%$ of maxillofacial trauma, and falls on a slippery ground is the most common cause in this age group $^{16}$.

It was evident that the facial bones fractures were uncommonly singular with compound and comminuted nature adding on to the complexity of facial fractures. It is a common concept of fracture nasal bone being the most common facial bone to be fractured, then the zygoma followed by mandible and maxilla. ${ }^{17}$

Apart from maxillofacial injury, high velocity impacts may result in fracture of facial bones and life threatening intracranial hemorrhages in different compartments requiring urgent neurosurgical intervention ${ }^{19}$. A decrease in the level of consciousness is the single most reliable indicator that the patient has a serious head injury or secondary insult to the brain ${ }^{20}$. Loss of consciousness is the manifestation of intracranial injury or concussion head injury (62\%), followed by headache $(33 \%)$, vomiting $(27 \%)$, nasal bleed $(30 \%)$ and oral bleed $(10 \%)^{21}$.

The Glasgow Coma Scale score(GCS) is used to quantify neurologic findings and it is widely accepted and a standardized method for evaluating level of consciousness depending on the score of the GCS head injury can be classified as very mild, mild, moderate and severe head injury. About intracranial lesions, contusion/ concussion, extradural hematoma, subdural hematoma, subarachnoid hematoma and intracerebral haematoma occurs most frequent$1 \mathrm{y}^{20}$.

Existing literature on the correlation of traumatic head injuries and maxillofacial trauma Is highly controversial. Some suggest that it is the facial skeleton that absorbs the energy of the trauma, protecting the brain from injury, whereas, others suggest that high energy trauma causing maxillofacial injury are high enough to cause concomitant head injury ${ }^{1,2,3,4}$. The purpose of this study was to evaluate the pattern of head injuries in Patients with maxillofacial trauma and to co relate the relationship between them.

\section{Material and methods:}

This was a descriptive type of cross-sectional study carried out at the department of Oral \& Maxillofacial Surgery, Bangabondhu Sheikh Mujib Medical University, Shahbag, Dhaka. The period of study was from 1st May 2010 to 30th April 2011. The patient's data were collected from Inpatient department of Neurosurgery, Dhaka Medical College \&Hospital and inpatient department of Oral and Maxillofacial Surgery, Bangabondhu Sheikh Mujib Medical University, Shahbag, Dhaka who were referred from other Neurosurgical center. The total of 60 patients who sustained both cranial and facial injuries were included in this study. After taking informed consent, data were collected by history, through clinical examination, radiographic evaluation and Neurosurgical consultation. Appropriate skull X-Rays were done in all patients and patients with impaired consciousness, neurological sign or clinical sign of basal skull fracture, an initial CT scan was also performed.

Information regarding age, gender, cause of injury, pattern of facial and/or head injuries, loss of consciousness, and GCS score were obtained and recorded in questionnaires.

The causes of injury were summarized as follows: Motor vehicle accidents, Fall from height, Pedestrian, Assault, Sports injuries, Work-related injuries, and others.

Facial injuries included facial bone fractures and/or soft tissue injuries. Facial bone fractures were classified as mandibular, Lefort I, Lefort II, Lefort III, Zygomatico-maxillary fracture including orbit, and Nasal bone fractures. The types of mandibular fractures were classified by anatomic site (condyle, ramus, angle, body, symphysis, parasymphyses and coronoid).

Head injuries included skull fractures and/or intracranial injuries. Skull fractures were classified into scalp injury, linear fracture and depressed fracture of frontal, temporal, parietal, occipital, and basal skull fractures. Intracranial injuries were summarized as concussion, cerebral contusion, and intracranial hemorrhage (epidural, subdural, intracerebral and subarachnoid).

Brain trauma was handled by Neurosurgery department and complex facial fractures were repaired by 
the Oral and Maxillofacial surgery Department.

\section{Statistical analysis}

After the patient had given consent to be included in the study, a standardized structured data collection sheet was used to collect necessary information of the study subject. The data were screened and checked for any missing value and discrepancy. The data were then processed and analyzed using statistical software SPSS (statistical Package for Social Science) version16. Chi- square test was carried out and significant level $p$ value of $<0.05$ was considered statistically significant. The summarized data were present in the form of tables, graphs and bar diagrams by the help of statistician.

\section{Results and Observation:}

Table-1: Age distribution of the study subjects $(n=60)$

\begin{tabular}{|c|c|c|}
\hline $\begin{array}{c}\text { Age group (in } \\
\text { years) }\end{array}$ & $\begin{array}{c}\text { Number of } \\
\text { patients }\end{array}$ & Percent \\
\hline $0-10$ & 3 & 5.0 \\
\hline $11-20$ & 5 & 8.3 \\
\hline $21-30$ & 31 & 51.7 \\
\hline $31-40$ & 14 & 23.3 \\
\hline $41-50$ & 3 & 5.0 \\
\hline $51-60$ & 2 & 3.3 \\
\hline $61-70$ & 2 & 3.3 \\
\hline Total & 60 & 100.0 \\
\hline
\end{tabular}

Mean $\pm S D=29.63 \pm 12.0$ Range $=(5-64$ years $)$

Majority of the victims were in the age group of 21 to 40 years $(75 \%)$, with $21-30$ years $(51.7 \%)$ more affected among this group. Children less than $10 \mathrm{yrs}$ and elderly $>60 y$ rs of age made up a less frequency.

\section{Graph 1: Age Distribution of the study subject $(n=60)$}

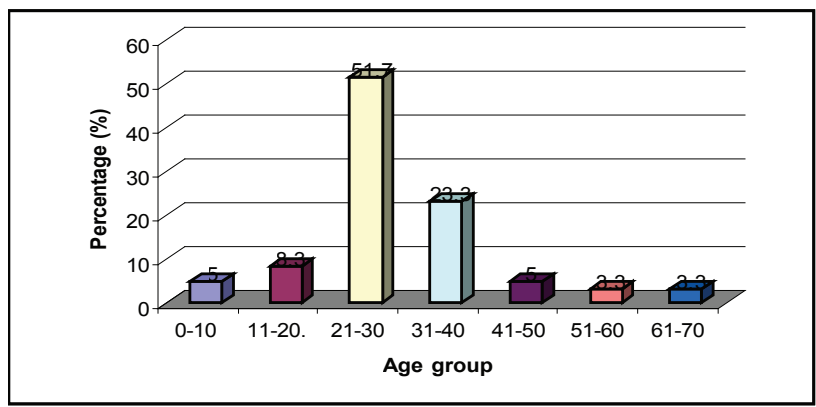

Above graph indicates that 21-30 years age group was more commonly affected.
Figure 1: Sex distribution of the patients $(n=60)$

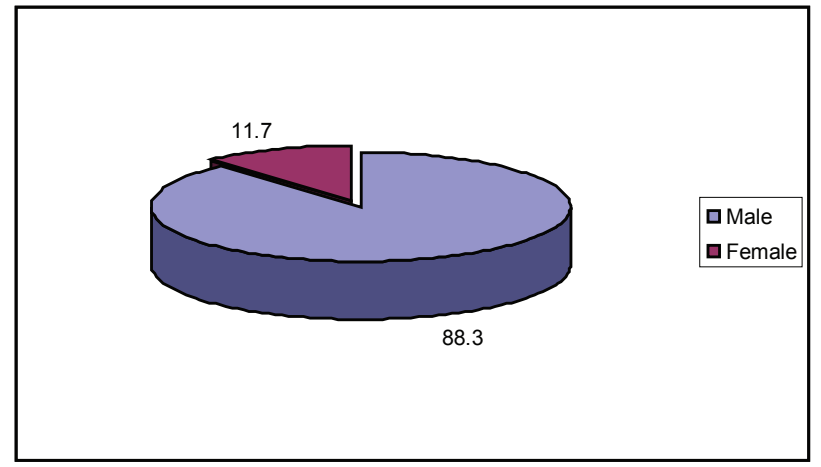

Fig-1: Shows that among patients with both maxillofacial and head injury $88.3 \%$ were male and $11.7 \%$ were female.

Table 2: Distribution of mode of injury $(n=60)$

\begin{tabular}{|c|c|c|}
\hline Mode of injury & $\begin{array}{c}\text { Number of } \\
\text { patients }\end{array}$ & Percent \\
\hline Motor vehicle & 36 & 60.0 \\
\hline Fall from height & 8 & 13.3 \\
\hline Pedestrian injury & 7 & 11.7 \\
\hline Assault & 5 & 8.3 \\
\hline Gunshot & 1 & 1.7 \\
\hline Sports & 2 & 3.3 \\
\hline Domestic violence & 1 & 1.7 \\
\hline Total & 60 & 100.0 \\
\hline
\end{tabular}

Table 2: indicates that majority of the victims suffered by motor vehicle accidents $(60 \%),(n=36)$ followed by fall from height $(13.3 \%)(n=8)$ and pedestrians (11.7\%), $(n=7)$.

\section{Graph 2: Distribution of Glasgow Coma Score (GCS)} of the patients $(n=60)$

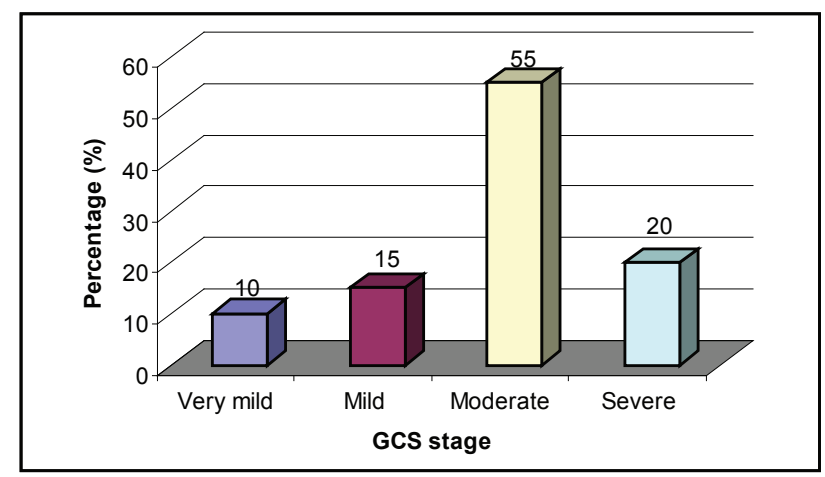

Above figure indicates that most of the study population suffered from moderate head injury (55\%), $(n=33)$, followed by severe head injury $(20 \%)(n=12)$, mild head injury $(15 \%)$, $(n=9)$ and very mild head injury $(10 \%)(n=6)$. 
Table 3: Distribution of fracture facial bones $(n=60)$

\begin{tabular}{|l|c|c|}
\hline & $\begin{array}{c}\text { Number } \\
\text { of patients }\end{array}$ & Percent \\
\hline Mandible Fracture (total- 22) & & 36.67 \\
Symphysis fracture & 4 & 6.7 \\
\hline Parasymphysis fracture & 2 & 3.3 \\
\hline Parasymphysis+condyle & 6 & 10.0 \\
\hline Angle of mandible & 7 & 11.6 \\
\hline Body of mandible & 1 & 1.7 \\
\hline Condyle fracture (isolated) & 2 & 3.3 \\
\hline Zygomatico-maxillary fracture including orbit & 11 & 18.3 \\
\hline Lefort-I & 6 & 10.0 \\
\hline Lefort-II & 11 & 18.3 \\
\hline Lefort-III & 7 & 11.7 \\
\hline Nasal bone fracture & 3 & 5.0 \\
\hline Total & 60 & 100.0 \\
\hline
\end{tabular}

Table-3: Shows mandible was the most commonly fractured facial bone $(36.67 \%)(n=22)$ at different anatomical locations. Both Zygomatico-maxillary complex fracture and Lefort-II fracture were equal frequency $18.3 \%(n=11)$.

Table-4: Distribution of involvement of cranium $(n=60)$

\begin{tabular}{|c|l|c|c|}
\hline \multicolumn{2}{|l|}{ Involvement of cranium } & $\begin{array}{c}\text { Number of } \\
\text { patients }\end{array}$ & Percent \\
\hline & Scalp injury & 14 & 23.3 \\
\hline & Linear fracture & 19 & 31.6 \\
\hline & Depressed fracture frontal bone & 10 & 16.6 \\
\hline & Depressed fracture temporal & 3 & 5.0 \\
\hline & Depressed fracture parietal & 2 & 3.33 \\
\hline & Depressed fracture occipital & 1 & 1.67 \\
\hline & Basal Skull Fracture & 0 & 0 \\
\hline & CSF Leakage & & 11.66 \\
& $\begin{array}{c}\text { Rhinorrhoea } \\
\text { Otorrhoea }\end{array}$ & 7 & 6.66 \\
\hline & Total & 60 & 100.0 \\
\hline
\end{tabular}

Table- 4: indicate that Linear fracture were more (31.6\%) $(n=19)$ then depressed fracture $(n=16)$ and scalp injury.

Figure-2: Distribution of type of head injury $(n=60)$

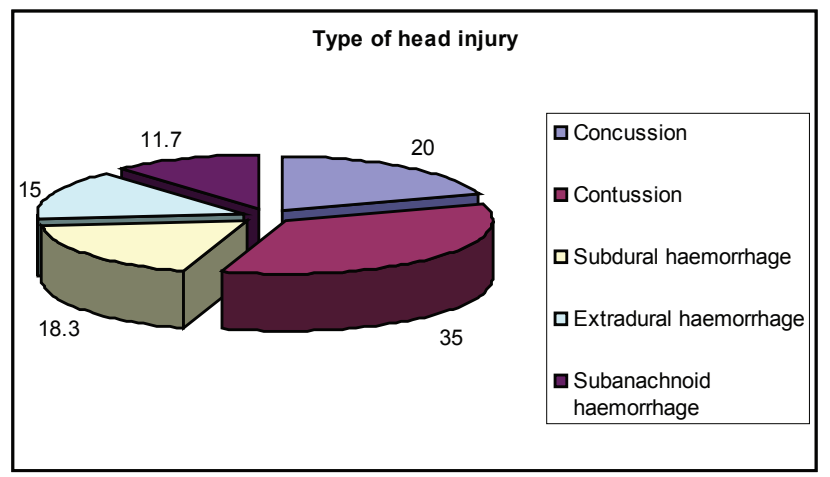

Above figure indicates that, most of the study population suffered from contussion (35\%) $(n=21) . \quad 18.3 \%$ had subdural hemorrhage $(n=11)$ and $15 \%$ had Extradural haemorrhage $(n=9)$.
Table-5: Cross tabulation between pattern of facial fracture and severity of head injury (n-60)

\begin{tabular}{|c|c|c|c|c|c|}
\hline \multirow{2}{*}{ Facial bone fracture } & \multicolumn{4}{|c|}{ GCS stage } & \multirow{2}{*}{$P$ value } \\
\hline & Very mild & Mild & Moderate & Severe & \\
\hline Parasymphysis fracture & 1 & 1 & 0 & 0 & \multirow{11}{*}{$0.002^{s}$} \\
\hline Parasymphysis+condyle & 2 & 2 & 2 & 0 & \\
\hline Symphysis fracture & 1 & 1 & 2 & 0 & \\
\hline Angle of mandible & 0 & 2 & 5 & 0 & \\
\hline $\begin{array}{ll}\begin{array}{l}\text { Condyle } \\
\text { (isolated) }\end{array} & \text { fracture } \\
\end{array}$ & 0 & 0 & 2 & 0 & \\
\hline Body of mandible & 1 & 0 & 0 & 0 & \\
\hline $\begin{array}{l}\text { Zygomatico-maxillary } \\
\text { fracture including orbit }\end{array}$ & 0 & 1 & 8 & 2 & \\
\hline Lefort-I & 0 & 2 & 4 & 0 & \\
\hline Lefort-II & 0 & 0 & 8 & 3 & \\
\hline Lefort-III & 0 & 0 & 0 & 7 & \\
\hline Nasal bone fracture & 1 & 0 & 2 & 0 & \\
\hline Total & 6 & 9 & 33 & 12 & 60 \\
\hline
\end{tabular}

Table-5: indicates that most of the zygomatic- maxillary complex fracture including orbit occurred in case of moderate head injury and most of the Lefort-II fracture occurred in patients with moderate and severe head injury. And most of the Lefort-III fracture occurred in patient with severe head injury.

Graph 3: Correlation between pattern of facial fracture and severity of head injury

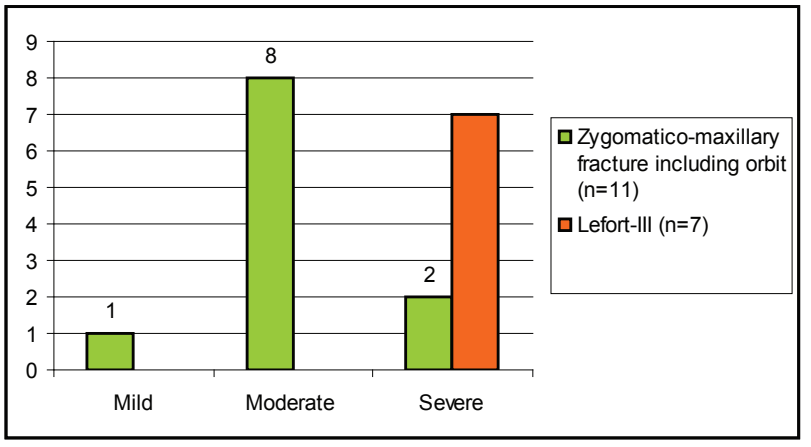

\section{Discussion:}

Bangladesh is a south Asian developing country where poverty and unemployment forcing the people towards urban areas. This rapid and unplanned urbanization associated with incompetent traffic system, unplanned roads and highways, violation of traffic laws by the drivers and pedestrian injury, overcrowding, etc are responsible for highest figure of road traffic accidents, and these RTA victims are mainly suffered from Craniofacial injury.

In the present study, majority of the head and concomitant facial injuries were experienced by males, constituted $88.3 \%$ and females constituted only $11.7 \%$ of the total victims. The male to female ratio was $7.57: 1$. These results are similar in a study from India, where $89 \%$ of subjects were males and $11 \%$ were females, giving a male to female ratio 
$8.09: 1^{12}$. This indicates that males are more prone to maxillofacial injury with or without head injury this high vulnerability of male gender for all type of trauma can be attributed to the fact that in our society males are predominantly the bread bearing for the family. Moreover they are at higher risk of injuries than women because of their greater exposure of automobile and motorcycle accident and engaged in more risky behavior like hanging on the side of the bus or rush to get in a running bus.

In our study, it was found that majority of patients were in the age group between 2nd to 4th decade and mean age was 29.63 years which is similar to other studies of the globe. ${ }^{21}$ The possible explanation for this is that the people in this age group take part in dangerous exercise and sports, drive motor vehicles carelessly and are more likely to be involved in violence. Patients less than 10 years and more than 60 years were less frequently affected in our series. These could be explained that children are usually taken care of by elders during travelling and lesser mobility of geriatric people. But the effect of head injury is disproportionately severe in elderly and they require more neurosurgical care.

The main causes of craniofacial injury worldwide are assaults and road traffic accidents, but the prevalence varies depending on the demographics and geography of the area. Road traffic accidents (RTA) are the commonest cause of craniofacial trauma in most of the series ${ }^{5,11,12,20}$ and this occurred largely in our circumstance also $(60 \%)$ because of recklessness and negligence of the drivers, poor maintenance of vehicles, often driving under the influence of alcohol or drugs and complete disregard of traffic laws. Fall from height was the second most common cause of injury in our series and attributed to $13.3 \%$, this occurred mostly in urban area where lot of peoples worked as a day labour in construction of high rise buildings and painting them. It is in accordance with others findings from South India, which reported $16,6 \%$ of Craniofacial trauma were due to fall from coconut tree.12 In our study, we found, pedestrians constituted $11.7 \%$ of the total victims. In Dhaka city, a large number of pedestrians are garments employees and day labor. They have lack of knowledge regarding traffic rules, shortage of space in footpath, most of which are occupied by the hawkers. Most of the pedestrians are not used to use the pedestrian's bridge. That's why pedertrain injury is a common cause of injury in our country. Domestic violence is another cause of craniofacial trauma in our country, where the women are most of the time beaten by her male partner and/or family members for dowry for other reasons. We found only $1.7 \%$ in our study.

Isolated mandible fractures are most common facial bone to be fractured ranging from $12.9 \%$ to as high as $72.9 \%$, followed by midface ranging from $25.9 \%$ to $29.5 \%^{11,12,21}$ the other frequently affected bones are the floor of the orbit and nasal bones. However, in the present series, the most frequent maxillofacial injury represented was the fractured mandible $36.6 \%$, followed by fractured Zygomatico-maxillary complex including orbit and Lefort fractures. In a survey by Malara $P$ et ai in 2006, they found in 198 patients that $18.69 \%$ suffered mandibular fracture, $12.63 \%$ Zygomatic complex fracture and $12.2 \%$ maxillary fractures ${ }^{22}$. Obuekwe and Etetafia in 2004 found in their study, that mandible was the most common site of fracture, followed by Zygomatic complex and maxilla ${ }^{23}$. The results of our study therefore correlate with other literatures.

In this study we found among LeFort fractures LeFort- II is more common (18.3\%), than LeFort III $(11.7 \%)$ and LeFort - I. The pattern is identical to studies conducted by Haug HR, Foss J. in $2000^{15}$. Our results demonstrated lower incidence of Nasal bone fracture (5\%), although it is a common concept of fracture Nasal bone is the most frequent facial bone to be fractured. It probably comes from the fact that isolated Nose fracture was managed by other specialties like ENT and Plastic Surgery.

GCS is a good marker for determining potential brain injury, clinical conditions and prognosis of the patients following trauma ${ }^{24}$. On the basis of GCS scores of the patients, It was found that, majority of patients with head injury according to their GCS score were classified as having moderate head injury $55 \%(n=33)$, followed by severe head injury $20 \%(n=12)$, mild head injury $15 \%(n=9)$, and minor head injury 10\% $(n=6)$ respectively. The results from this study showed a significantly higher incidence of moderate type of head injuries associated with maxillofacial injuries as compared to other reports in the English literature.

In case of head injury, various pattern of skull fracture were found. Linear fracture was the commonest type $(31.6 \%)$ followed by depressed fracture $(26.6 \%)$. Linear fracture was the commonest one because during RTA head strikes by forcible contact with broad resting surface like roads ${ }^{18}$. This result was identical to other study done by Ahmed et al in 2009 in Bangladesh. ${ }^{20}$ Regarding depressed fracture of individual bones, Frontal was most prone to fracture $(16.66 \%)$ followed by fracture temporal bone $(5 \%)$ and parietal 
bone. This coincides with other study done previously at BSMMU in Bangladesh in 2002. ${ }^{25}$

In agreement with a study by Pappachan and Alexander, we observed that CSF rhinorrhoea was nearly twice as frequent as CSF otorrhoea. ${ }^{27}$ This may be explained by the fact that anterior Cranial base is relatively closer to midfacial structures and has more sutural connection with midfacial bones compared to the middle cranial base. Thus, the chance of anterior cranial base fracture and resulting CSF rhinorrhoea is expected to be higher.

Similar to other studies the most common neurological symptom was loss of consciousness, which can be manifestation of intracranial injury or concussion head injury 18,24 which was also more common in patients with fracture of the upper face ${ }^{21,24}$ moreover loss of consciousness is less common with isolated facial fractures. Gwynn et al found that life threatening injuries such as cerebral concussion were frequently associated with facial fractures ${ }^{26}$ which support the result of our study. We found that $35 \%$ patient had cerebral contusion. But at the same time, as in present series, all patients who sustain moderate or severe head injury also, had associated intracranial injuries reflecting the severity and complexity of craniofacial trauma. ${ }^{18}$

Apart from maxillofacial fractures, high velocity impacts may result in ruptures of intracranial vessels, leading to life-threatening intracranial hemorrhage, Intracranial hemorrhage was found in $45 \%$ cases in present study, which was more as compared to previous studies ${ }^{28}$. This may be due to the difference in the mode and severity of injuries.

About intracranial lesions most of the victims had subdural haemorrhage $18.3 \%$, followed by extradural haemorrhage $(15 \%)$, and subarachnoid haemorrhage $(11.7 \%)$. In a study from India by Ashok KG et al, showed that $5 \%$ victims had subdural haemorrhage $14 \%$ had subarachnoid haemorrhage and $13 \%$ had extradural haemorrhage ${ }^{14}$ which is identical to our study.

The results of previous studied evaluating the relationship between facial and head injuries are conflicting. Hohlrieder et al reported that Le Fort- II and III, Orbit, Nose,, Zygoma and Maxillary fractures were associated with a 2-to 4 fold risk of intracranial hemorrhage, while mandibular fracture did not significantly increases the chance of intracranial hemorrhage $^{21}$. Haug et al. reported that although the mandible was the most frequent fractured bone in patients with concomitant facial and head injuries, midface fractures were more frequently associated with closed head injuries than mandible fracture..$^{19}$ These difference in the facial bone or head injury being studied and the variation in classification, nomenclature or methodology of prior studies may explain these conflicting result. In the present study we demonstrated that LeFort- III fracture was the strongest predictor of severe head injury, followed by LeFort- II and Zygomatico-maxillary fracture including Orbit this coincide with the other findings done by Kloss et al. reported that LeFort- III fracture was the strongest predictor of intracranial bleeding.

\section{Conclusion}

Adult males in the age group of 20-40 years were the most common victims of craniofacial trauma. Road traffic accidents were responsible for the majority and most of the patients sustained moderate head injuries that were then managed conservatively. Fracture mandible was the most common maxillofacial injury .More severe were the maxillofacial injury more were the chances of neurological injury. Fracture of the mid-face was found to be most commonly associated with head injury and the management of both neurological and maxillofacial injury was done according to the necessity.

\section{Recommendations:}

In view of the high association of closed head injury in the facial fracture population, as well as high potentiality for mortality and neurological morbidity the authors of present study recommend the routine use of head CT for all patients sustaining a facial trauma and close monitoring of neurological status of these patients.

\section{Consent for the study}

- All patients or relatives were given a necessary explanation about the study before they asked to participate.

- For those patients who were unconscious, consents were obtained from their relatives.

- For patients under ages 18 years, informed consents were obtained from their parents/ guardians.

\section{References:}

1. Sharmin FN, Cameron $P$ et al. Maxillofacial trauma in major trauma patients. Aus Den Journ. 2006; 51(3):225-230.

2. Follmar KE, Debruijn M, Baccarant A, Bruno AD, Mukundan S, Erdmann $D$ et al Concomitantinjuries in patients 
with panfacial fractures. J Trauma. 2007; 63:831-5.

3. Lim LH, Lam LK, Moore MH, Trott JA, David DJ. Associated injuries in facial fractures: review of839 patients. $\mathrm{Br} \mathrm{J}$ Plast Surg. 1993;46:635-8.

4. Mulligan RP, Friedman JA, Mababir BC. A nationwide review of the associations among cervical spine injuries, head injuries, and facial fractures. J Trauma. 2010;68:587-92.

5. Gwyn PP, Carraway JH, Horton CE, Adamson JE, Mladick BA. Facial fractures-associated injuries and complications. Plast Reconstr Surg. 1971;47:225-30.

6. Kloss $F$, Laimer $\mathrm{K}$, Hohlrieder $\mathrm{M}$, Ulmer $\mathrm{H}$, Hacki $\mathrm{W}$, Benzer A, et al. Traumatic intracranial haemorrhage in conscious patients with facial fractures-a review of 1959 cases. Craniomaxillofac Surg. 2008;36:372-7.

7. Adeyemo $\mathrm{WL}$, Ladeinde $\mathrm{AL}$, Ogunlewe $\mathrm{MO}$, James O.Trends and characteristics of oral and maxillofacial injuries in Nigeria: a review of the literature. Head Face Med. 2005; 1:7.

8. Van Hoof RF, Merkx CA, Stekelenburg SC. The different patterns of fractures of the facial skeleton in four European countries. Int J Oral Surg.1977; 6 (1): 3-11.

9. Brown RD. Cowpe JG. Patterns of maxillofacial trauma in two different cultures: Acomparison:between Riyad and Tayside. JR Coil surg Edinb.1985; 30(5): 299-302.

10. King RE, Scianna JM, Petruzzelli GJ. Mandible fracture patterns: A suburban trauma center experience. An J Otolaryngol. 2004; 25 (5): 301-307.

11. Ansari $\mathrm{MH}$. Maxillofacial fractures in Hamedan provience, Iran: A retrospective study (1987-2001). J Craniomaxilloac Surg.2004; 32 (I): 28-32.

12. Rajendra PB, Mathew TP, Agrawal A, Sabharawal G. Characteristics of associated trauma in patients with head injuries: An experience with 100 cases. J Trauma and Shock. 2009; 2(2): 89-94.

13. Adekeye SO. The pattern of fracture of facial skeleton in Kaduna Nigeria. A survey of 1447 cases. Oral Surg. 1980; 49(6): 491- 495.

14. Ashok KG, Ran'ineesh G, Asish C. A retrospective analysis of 189 patients of maxillofacial injuries presenting to a tertiary care hospital in Punjab, India. J Maxillofac Oral Burg. 2009; Sep;8(3):241-5.

15. Haug RH, Foss J. Maxillofacial injuries in the pediatric patient. Oral Surg Oral Med Oral Pathol of Oral Radio Endod. 2000; 90:126-134.
16. Rehman $\mathrm{K}$, Edmcndson $\mathrm{H}$. The causes and consequences of maxillofacial injuries in elderly people. Gerodontology. 2002; 19:60-64.

17. Khan AR, Arif S. Ear nose and throat injuries in children. J Ayub Med Coll Abbottabad.2005; 17:54-6.

18. Davidoff $G$, Jakubowski $M$, et al. The spectrum of closed- head injuries in facial trauma victims:incidence and impact. Ann Emerg Med.1998; 17:6-9.

19. Egol R, Fromm KR, et al. Guideline for intensive care unit admission, discharge, and triage. Cr/f Care Med 1992; 27:633-638.

20. Ahmad M, Rahman FN, Chowdhury MH, et al. Postmortem study of head injury in fatal road: traffic accidents. JAFMC.2009; 5 :(2):24-28.

21. Pradeep G, Ankit J, Nirmal K G. Association of Head injury and Maxillofacial Trauma: A prospective CaseControl study. Indian journal of Applied Research. 2016; 6(3): 528-531.

22.Malara P, Malara B et al:characteristics of maxillofacial trauma resulting from road traffic accidents- a 5years review. Head and Face medicine. 2006:2:27.

23. Obuekwe ON, Ojo MA, Akpata O. Maxillofacial trauma due to road traffic accidents in Benin City, Nigeria: A prospective study. Annals of African Medicine. 2003; 2(2): 58-63.

24. Haug RH, Savage JD, Likavec MJ, Conforti PJ. A review of 100 closed head injuriesassociated with facial fractures. J Oral Maxillofac Surg. 1992;50:218-22.

25. Chowdhury D. Depressed skull fractures: analysis of clinical outcome and cost effectiveness of timely surgical management. MS (Neurosurgery) thesis, BSMMU, 2002.

26. Gwynn P, Carraway JH, Horton CE, et al: Facial fractures-associated injuries and complications. Plast and Reconstr Surg. 1971; 47: 225-230.

27. Pappachan B,Alexander M. Correlating facial fractures and Cranial Injuries. J Oral Maxillofacial Surg. 2006; 64:1023-1029.

28. Zandi M, HoseiniSR. The relationship between head injury and facial trauma: a case- control study. J oral and maxillofacial surgery. 2013; 7(3):201-207. 